\title{
RADIOGRAPHIC EVALUATION OF PLATFORM SWITCHING IMPLANT ABUTMENTS RESTORED BY TWO METAL FREE RESTORATIONS
}

\author{
Ahmed E. Abd Elmonam ${ }^{1 *}$, Hesham E. Othman ${ }^{2}$, Mohammed F. Metawlly ${ }^{3}$
}

\begin{abstract}
Objective: The objective of this study was to evaluate the radiographic effect of two abutment materials with two different types of superstructure metal free restorations on the platform switched implant. Subjects and Methods: Twenty human patients with missing maxillary central incisor were selected for implant placement and divided randomly into two groups according to abutment type; titanium and PEEK abutment $(n=10$ in each). Each group was subdivided into two subgroubs according to superstructure crown (PEEK and VITA ENAMIC crowns, $n=5$ in each). All groups were evaluated radiographically. Preapical radiographs were taken by parlling technique at baseline, 3, 6 and 12 months. Results: The mean value of marginal bone level were determined that PEEK PEEK group showed a lower Mean marginal bone loss, followed by PEEK VIT , followed by Ti PEEK, while Ti VIT was the highest $(0.64 \pm 0.03,0.67 \pm 0.02,0.96 \pm 0.04,1.01 \pm 0.05$, respectively). Regarding each other PEEK PEEK and PEEK VIT groups were significantly lower than Ti VIT group. Conclusion: PEEK abutment is considered a better alternative to titanium abutment in relation to hard tissue response in addition to having a good role in occlusal force distribution as marginal bone loss was reduced when PEEK abutments were used compared to titanium abutments regardless of the type of suberstructure crown.
\end{abstract}

KEYWORDS: Dental implant, implant abutment, PEEK, VITA ENAMIC.

\section{INTRODUCTION}

Dental implants are one of the most exciting treatments in modern dentistry. Unlike crowns, bridges or veneers, which attach to existing teeth, dental implants replace lost or damaged teeth entirely by connecting a fixture directly into the jawbone by osteointegration and attaching a fully functional esthetic tooth ${ }^{(1)}$.

Titanium (Ti) and its alloys have been used as dental implants since Brånemark introduced them at the end of the $1960 \mathrm{~s}^{(2)}$.Ti materials possess good physicochemical characteristics, mechanical properties, biocompatibility, and high resistance to fatigue stress and corrosion ${ }^{(3,4)}$. However, Ti materials have an elastic modulus significantly higher than that of bone (titanium: $110 \mathrm{GPa}$; cortical bone: $14 \mathrm{GPa}$ ), and the difference may result in inadequate stress shielding, bone resorption, and implant fracture ${ }^{(5,6)}$. In addition, certain studies have shown that titanium is an allergen and can cause allergic reaction to the patient ${ }^{(7)}$.

Poly ether ether ketone (PEEK) has some clinical advantages as a dental implant material compared

1. Assistant lecturer, Crown and Bridge Department Faculty of Dental Medicine, Al-Azhar University. Cairo, Egypt

2. Professor, Crown and Bridge Department Faculty of Dental Medicine, Al-Azhar University. Cairo, Egypt

3. Lecturer, Crown and Bridge Department Faculty of Dental Medicine, Al-Azhar University. Cairo, Egypt

-Corresponding author: dr_elwanahmed87@yahoo.com

DOI: $10.21608 /$ ajdsm.2020.45289.1121 
to Ti. Firstly, it causes fewer hypersensitive and allergic reactions. Secondly, it is radiolucent and causes fewer artifacts on magnetic resonance imaging ${ }^{(5,8)}$. Thirdly, it does not have a metallic color; it is beige with a touch of gray, and has a more aesthetic appearance than Ti especially in anterior zone. Fourthly, PEEK is a versatile foundation material that can be tailored to a particular purpose by changing its bulk or surface properties. PEEK can be used as an implant material in the implant body, abutment, and superstructure ${ }^{(8)}$.

ENAMIC is a hybrid ceramic produced by VITA (Germany). The ceramic part consists of an aluminum oxide enriched, fine structure feldspar matrix (86 wt.\%) infused by a polymer material consisting of (14 wt\%) urethane dimethacrylate and triethylene glycol dimethacrylate. It has a flexural strength of $151 \mathrm{MPa} .{ }^{(9)}$ Both advantages of ceramic and resin materials are combined in ceramic/ polymer materials such as less brittleness, excellent machinability and edge stability ${ }^{(9)}$.

The concept of platform switching (PS) is based on the placement of a narrow diameter abutment on a wider diameter implant. Implants placed according to this concept have implant abutment junction placed closer to the center of the implant ${ }^{(10)}$. The radiographically detectable perimplant bone level following prosthetic loading is considered one of the relevant success criteria for evaluating dental implant therapy outcomes as well as for proving or excluding perimplant tissue health ${ }^{(11,12)}$. Once accepting a marginal bone loss of up to $1.5 \mathrm{~mm}$ during the first year, followed by a bone loss not exceeding $0.2 \mathrm{~mm}$ per year ${ }^{(13)}$.

Both histomorphometric studies and three dimensional finite element models have showed the potential role of PS configuration to limit the perimplant marginal bone resorption, optimizing spaces for the biological width components ${ }^{(14)}$, medializing implant-abutment microgap and inflammatory cell infiltrate ${ }^{(15)}$, and shifting the area of maximum biomechanical stress towards implant central axis ${ }^{(16,17)}$. Therefore, the hypothesis of this study was that the marginal bone level will be affected by peek or titanium abutment whatever the type of superstructure restorative materials.

\section{SUBJECTS AND METHODS}

This study included twenty systemically healthy patients ( 12 females and 8 males, ranged in age from 20-50 years with mean age of 35.5 years) with a missing anterior maxillary central incisor requiring a $\left(3.75^{*} 11\right)$ implant placement. All patients were selected from those attending at the OutPatient Clinic, Oral Medicine and Periodontology Department, Faculty of Dental Medicine, Al-Azhar University.

Inclusion criteria: Patients' being free from any systemic disease, of both sexes, absence of any infection or periodontitis in the area that will receive the implant.

Exclusion criteria: Patients with any major or minor systemic diseases, Pregnancy, Patients with parafunctional habits, Poor oral hygiene, lack of motivation, and smokers.

Ethical Considerations: Patients enrolled in this study signed in written consent form and acceptance from the ethical committee with the reference number 533/1604. Patients were randomly classified into 2 groups $(n=10)$ according to the material type of the platform switched abutment. The First group received Titanium abutment (Ti) (Flotecno implant system, Itay), while the second group received Poly ether ether ketone abutment (PEEK) (Bredent, Germany). Each group was further subdivided into two subgroup $(n=5)$ according to superstructure crown materials, PEEK superstructure (Bredent, Germany) crown groups with titanium and peek abutment (Ti PEEK ,PEEK PEEK), and VITA ENAMIC superstructure (VITA Zahnfabrik, Germany) crown groups titanium and peek abutment (Ti VIT, and PEEK VIT). 
Pre-surgical Evaluation: Preoperative Computed Tomogram Scanner (Siemens SOMATOM Scope 16-Slice computed tomogram Scanner ${ }^{\circledR}$ Siemens, Erlangen, Germany) was carried out to the patients before the intervention to assess bone quality, quantity and density, to quantify the ridge height and width of the supporting bone. Oral hygiene measurements, instructions and reinforcement were performed at the end of the appointment. Standardized periapical radiographs of the implant site by a loop film holder (Rinn, DENTSPLY Australia Pty. Ltd, Mount Waverley, Australia) were taken using the long cone paralleling technique and condensation silicon occlusal template. The occlusal template is constructed for each patient and was kept for reuse during each follow up visit as a means of standardization for radiographic evaluation of the implant.

Surgical procedures: The preoperative medications included the patient rinsed with Chlorhexidine gluconate $0.1 \%$ to reduce the bacterial load. Local anesthesia was administrated, the surgical site was anesthetized using Mepecaine ${ }^{\circledR}$ L 2\% (Alexandria Co. for Pharmaceuticals, Alexandria, Egypt). Sequential drilling was done using a surgical stent as a surgical guide, after a full thickness labial and palatal mucoperiosteal flap reflection was done. Pilot drilling for the most correct anatomical positioning of the planned dental implants was initiated. Preparation of the implant site continued with the continuous drilling until final drill was reached, then insert the fixture of the implant $3.75 * 11 \mathrm{~mm}$. Standard implant is placed in the site, the implant shoulder to be located at the bony level and reevaluate by periapical radiograph. The final wound closure performed by interrupted $0 / 3$ non resorpable sutures were removed between 10 and 14 days after surgery. After 3 months, healing period, the patients were called back for the second stage surgery. Healing abutments were tightened for 15 days. Afterwards, the final abutment was placed and checked the need for angled abutment or not in addition to evaluation of implant abutment connection. Closed tray impression technique was used using additional silicone impression material (Elite HD+, Zhermack, Badia Polesine, Italy). Through impression post and analog to transfer the hard and soft tissue relationship to the laboratory technician for fabrication of superstructure crowns .The final crown (PEEK or VITA ENAMIC) for each case was examined clinically and radigraphically. Clinical evaluation for the checking of the seating of the crown, marginal adaptation, occlusion, anatomical features and contours, and color matching. Radiographical evaluation for checking the marginal adaption between abutment finish line and margin of the restoration, removal of excess cement after cementation of final crown by long lasting Provitemp (Itena, France) temporary cement for retrivability of the restoration. Radiographic evaluation was done through a loop film holder when a radiograph was taken using the long cone paralleling technique and a condensation silicon occlusal template at baseline, 3, 6 and 12 months follow up periods.

Marginal bone loss around the implant was evaluated using periapical radiographs (Image plate sensor size 2 that analyzed by photon collection system of vista-scan $\left({ }^{\circledR}\right)$ that were taken on the day of the implant placement (baseline) and on the follow up visits at 3,6 and 12 month. The distance from a reference point at the implant which represented by the implant shoulder (plateform) to the most coronal point where the marginal bone contacts the implant was measure. Measurements were made mesially and distally in each implant. (Figure 1).

Statistical analysis was done using IBM SPSS software package version 20.0. (Armonk, NY: IBM Corp). The Kolmogorov-Smirnov test was used to verify the normality of distribution. Quantitative data were described using range (minimum and maximum), mean, standard deviation and median. Significance of the obtained results was judged at the $5 \%$ level. 


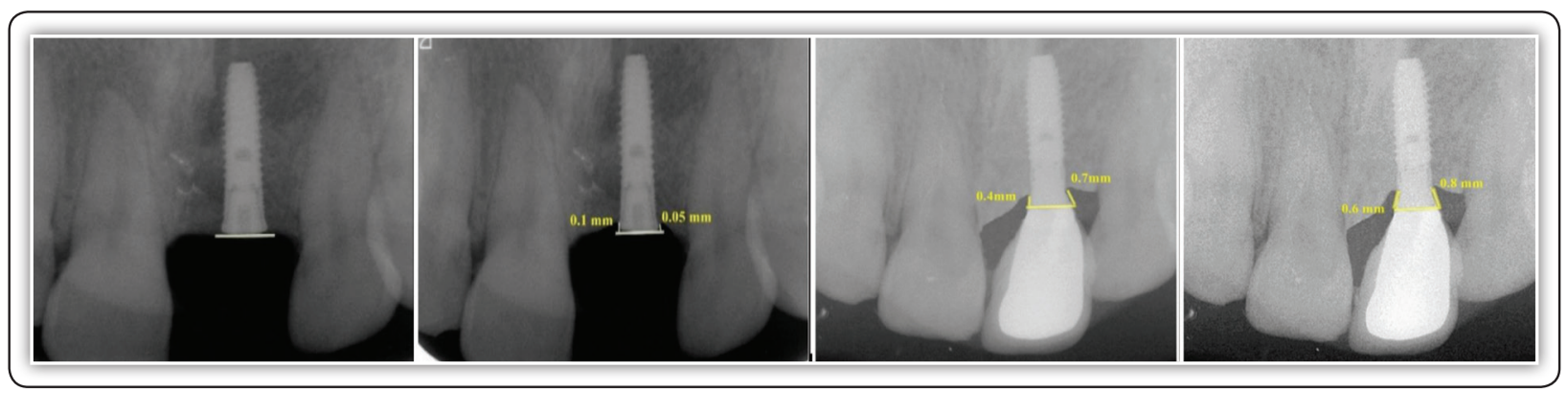

FIG (1) Periapical radiographs showing measurements of marginal bone loss

\section{RESULT}

At 3 months, the difference was statistically significant. PEEK PEEK showed a lower mean marginal bone level, followed by Ti PEEK, followed by PEEK VIT, while Ti VIT was the highest. Regarding with each other PEEK PEEK was significantly lower than Ti VIT and PEEK VIT. At 6 months, the difference was statistically significant. PEEK PEEK showed a lower mean marginal bone level, followed by Ti PEEK, followed by PEEK
VIT. Ti VIT was the highest. Regarding with each other PEEK PEEK was significantly lower than Ti VIT and PEEK VIT. Ti VIT was significantly lower than PEEK VIT. At 12 months, the difference was statistically significant. PEEK PEEK showed a lower mean marginal bone level, followed by PEEK VIT, followed by Ti PEEK, while Ti VIT was the highest. Regarding with each other PEEK PEEK was significantly lower than Ti PEEK. PEEK VIT was significantly lower than Ti VIT. (Table 1 and Figure 2).

TABLE (1) Comparison between the four studied subgroups according to marginal bone loss.

\begin{tabular}{|c|c|c|c|c|c|c|}
\hline Marginal bone level & $\begin{array}{c}\text { Ti PEEK } \\
(\mathrm{n}=5)\end{array}$ & $\begin{array}{c}\text { Ti VIT } \\
(\mathrm{n}=5)\end{array}$ & $\begin{array}{c}\text { PEEK PEEK } \\
(\mathrm{n}=5)\end{array}$ & $\begin{array}{c}\text { PEEK VIT } \\
(\mathrm{n}=5)\end{array}$ & F & $\mathrm{p}$ \\
\hline Baseline & $0.0 \pm 0.0$ & $0.0 \pm 0.0$ & $0.0 \pm 0.0$ & $0.0 \pm 0.0$ & - & - \\
\hline 3 months & $0.15 \pm 0.04$ & $0.25 \pm 0.04$ & $0.13 \pm 0.02$ & $0.24 \pm 0.03$ & $18.091^{*}$ & $<0.001^{*}$ \\
\hline Sig. bet. grps. & & \multicolumn{2}{|c|}{$\mathrm{p}_{1}<0.001^{*}, \mathrm{p}_{2}=0.980, \mathrm{p}_{3}<0.001^{*}$} & & \\
\hline 6 months & $0.44 \pm 0.02$ & $0.53 \pm 0.02$ & $0.34 \pm 0.03$ & $0.44 \pm 0.03$ & $48.999^{*}$ & $<0.001^{*}$ \\
\hline Sig. bet. grps. & & \multicolumn{2}{|c|}{$\mathrm{p}_{1}<0.001^{*}, \mathrm{p}_{2}<0.001^{*}, \mathrm{p}_{3}<0.001^{*}$} & & \\
\hline 12 months & $0.96 \pm 0.04$ & $1.01 \pm 0.05$ & $0.64 \pm 0.03$ & $0.67 \pm 0.02$ & $141.88^{*}$ & $<0.001^{*}$ \\
\hline Sig. bet. grps. & \multicolumn{2}{|c|}{$\mathrm{p}_{1}<0.001^{*}, \mathrm{p}_{2}<0.001^{*}, \mathrm{p}_{3}=0.677$} & & \\
\hline
\end{tabular}

Data was expressed by using Mean \pm SD.

F: F for ANOVA test, Pairwise comparison bet. each 2 groups was done using Post Hoc Test (Tukey)

$p: p$ value for comparing between the studied groups

$p_{1}: p$ value for comparing between $\mathbf{T i}$ vit and Peek peek

$p_{2}: p$ value for comparing between $\mathbf{T i}$ vit and Peek vit

$p_{3}: p$ value for comparing between Peek peek and Peek vit

*: Statistically significant at $p \leq 0.05$ 


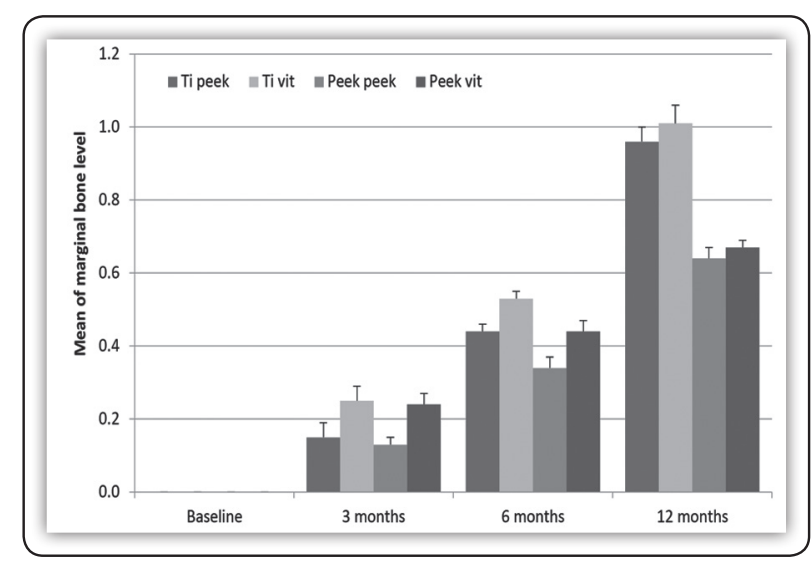

FIG (2) Comparison between the four studied groups according to marginal bone level

\section{DISCUSSION}

The occlusal forces are transmitted to the prosthesis, implant, and the bone around the implant, respectively. Therefore, the direction and amount of the load, the prosthetic material, the design of the prosthesis, the implant material, the design of the implant, the number of implants, and the mechanism of bone implant interface, bone type, and bone characteristics can be listed as factors affecting the load on the bone ${ }^{(18,19)}$. Prosthetic design and material selection affect the distribution of stress on prosthetic structures, implants, and bones. These stresses can lead to bone resorption around the implant and loss of implants ${ }^{(18,20)}$.

One of the most important features of PEEK material is low elastic modulus like the bone. Due to this feature, the material is considered to be used in fixed prosthetic treatments ${ }^{(21)}$. PEEK is a very light ${ }^{(22)}$, flexible, and hard to break material. The PEEK material's cost-efficiency and its feature of easy to be processed in the mouth also support its use ${ }^{(23)}$.

Therefore, in this study titanium implant was used with ready-made titanium abutment and customized hybrid PEEK abutments. This customization will help recreate the desired emergence profile, enhancing the formation of proper mucosal topography and coronal contours for prosthetic replacement. Since PEEK is lighter, it may be a suitable alternative to metal supported ceramics. They also do not cause galvanic elements (corrosion) when they contact other metals in the mouth ${ }^{(24)}$. It has been suggested that PEEK material alleviates the forces generated during chewing due to its elasticity ${ }^{(25)}$. When all groups are examined in accordance with the results obtained in this study, it was observed that in our study the use of PEEK crowns and abutment make a difference in terms of stresses on bones and implants.

This concept can best be recognized during the observation of final readings of marginal bone level, at 12 months, when the difference became statistically significant. PEEK PEEK group showed a lower mean marginal bone level followed by PEEK VIT then Ti PEEK group, while the Ti VIT was the highest. Regarding the previous results, not only the peek crown had a role in reducing marginal bone loss, but also the type of abutment had an effect on distributing the occlusal force over implant and so on reducing marginal bone resorption.

Tekin et al (26) approved that the use of PEEK crowns reduced the stress on itself and abutments. When the PEEK crown was used on titanium abutments, the stress on screw was decreased and when it was used on PEEK abutment, the stress was increased. It was known that the use of PEEK material reduced the stresses resulting from the applied forces on itself. Because of its low solubility in water and low reactivity with other substances, PEEK may also be suitable for patients with metal allergy or susceptibility to metallic taste.

Many materials have been used in the production of implant abutments. The abutments made up titanium, gold, zirconium are among these materials ${ }^{(27)}$. Although the use of titanium is controversial in terms of its susceptibility to corrosion and the hypersensitivity to it, titanium is the first preferred material in implantology and is 
considered the gold standard ${ }^{(28)}$. The desired results cannot be obtained in cases where the aesthetic is of top priority. Especially in the presence of thin gingival biotype, it creates esthetic problems ${ }^{(29)}$. It has been suggested that PEEK material may promote the remodeling process of the bone and it has been stated that PEEK material may be an appropriate alternative to titanium in abutment construction ${ }^{(24)}$. Since they have a high elastic modulus of titanium, they do not have the ability to absorb the shock during chewing loads ${ }^{(30)}$.

Since the elastic modulus of the PEEK material is very close to the bone, it has been suggested that it absorbs the incoming forces and minimizes the stresses on the bone. As a rigid structure can transmit the loads exposed by implant to the bone, it causes bone resorption. At this point, it has been stated that PEEK material has the advantage of protecting the bone structure by absorbing some of the stresses ${ }^{(31)}$. This is in agreement with the results obtained in the present study as mention before the use of peek abutment has a good effect on marginal bone level than titanium abutment.

The hypothesis of this study that the marginal bone level will be affected by PEEK or titanium abutments regardless of the type of superstructure restorative materials was accepted. This is because the marginal bone loss was affected by the type of the abutment. The limitation of the present study is that short follow up period. Future research is needed with longer follow up periods. The use of more than two types of abutments and crowns is also recommended. Within the limitations of this study it concluded that, the use of PEEK abutment is considered a better alternative to titanium abutment in relation to hard tissue response. In addition to having a good role in occlusal force distribution, marginal bone loss was reduced when PEEK abutments were used compared to titanium abutments, regardless of the type of superstructure crown.

\section{REFERENCES}

1. Ismaiel M, Elhadry A. Influence of platform switching concept on marginal bone alteration around dental implant. J Am Sci 2012;8(11):546-52.

2. Brånemark, P.I, Adell, R, Breine, U, Hansson, B.O, Lindstrom J, Ohlsson, A. Intraosseous anchorage of dental prostheses. I. Experimental studies. Scand. J. Plast. Reconstr. Surg. 1969; 3: 81-100.

3. Lautenschlager E.P, Monaghan P. Titanium and titanium alloys as dental materials. Int. Dent. J. 1993; 43: 245-253.

4. Renouard F, Nisand D. Impact of implant length and diameter on survival rates. Clin. Oral Implants Res. 2006; 17: $35-51$

5. Lee W.T., Koak J.Y., Lim Y.J., Kim S.K., Kwon H.B., Kim M.J. Stress shielding and fatigue limits of poly-etherether-ketone dental implants. J. Biomed. Mater. Res. B Appl. Biomater. 2012; 100: 1044-1052.

6. Huiskes, R., Ruimerman R., Van Lenthe G.H., Janssen J.D. Effects of mechanical forces on maintenance and adaptation of form in trabecular bone. Nature 2000; 405: 704-706

7. Manish G., Chandu G.,Sunil K.M., Siddharth G. Titanium allergy: A literature review. Indian J. Dermatol. 2014; 59- 630 .

8. Wang, H, Zhang W., Kwok D.T., Jiang, J., Chu, P.K. Mechanical and biological characteristics of diamond-like carbon coated poly aryl-ether-ether-ketone. Biomaterials 2010; 31: 8181-8187.

9. Spitznagel FA, Horvath SD, Guess PC, Blatz MB. Resin bond to indirect composite and new ceramic/polymer materials: a review of the literature. J Esthet Restor Dent. 2014;26(6):382-93

10. Al Amri MD, Abduljabbar TS. Comparison of clinical and radiographic status of platform-switched implants placed in patients with and without type 2 diabetes mellitus: a 24-month follow-up longitudinal study. Clin Oral Implants Res. 2017; 28(2):226-230

11. Papaspyridakos P, Chen C-J, Singh M, Weber H-P, Gallucci GO. Success criteria in implant dentistry a systematic review. J Dent Res. 2012;91(3):242-8.

12. . Albrektsson, Tomas. "On Crestal/Marginal Bone Loss Around Dental Implants." The International Journal of Prosthodontics. 2012: 320-322.

13. Eriksson AR. The long-term efficacy of currently used dental implants: a review and proposed criteria of success. Int J oral Maxillofac Implant. 1986;1:11-25. 
14. Degidi M, Iezzi G, Scarano A, Piattelli A. Immediately loaded titanium implant with a tissue-stabilizing/maintaining design (beyond platform switch) retrieved from man after 4 weeks: a histological and histomorphometrical evaluation. A case report. Clin Oral Implants Res. 2008;19(3):276-82.

15. Luongo R, Traini T, Guidone PC, Bianco G, Cocchetto $\mathrm{R}$, Celletti R. Hard and soft tissue responses to the platform-switching technique. Int J Periodontics Restor Dent. 2008;28:551-557.

16. Maeda Y, Miura J, Taki I, Sogo M. Biomechanical analysis on platform switching: is there any biomechanical rationale? Clin Oral Implants Res. 2007;18(5):581-4.

17. Chang C, Chen C, Hsu M. Biomechanical effect of platform switching in implant dentistry: a three-dimensional finite element analysis. Int J Oral Maxillofac Implants. 2010;25(2):295- 299.

18. Misch CE, St. Louis. Dental Implant Prosthetics Book. 2nd ed.2014;2: 46-65.

19. Pesqueira AA, Goiato MC, Filho HG, MonteiroDR ,Santos DM, Haddad MF. Use of stress analysis methods to evaluate the biomechanics of oral rehabilitation with implants. J Oral Implantol 2014;40:217-28.3.

20. Şahin S, Çehreli MC, Yalçın E. The in uence of functional forces on the biomechanics of implant-supported prostheses-A review. J Dent 2002;30:271-82

21. Najeeb S, Khurshid Z, Matinlinna JP, Siddiqui F, Nassani MZ, Baroudi K. Nanomodified peek dental implants: Bioactive composites and surface modification-A review. Int $\mathrm{J}$ Dent 2015;38:17-59.

22. Siewert B, Parra M, A new group of maretial in dentistry.
PEEK as a framework material for 12-piece implant- supported bridges. Zahnarztl Implantol 2013;29:148-59.

23. Kurtz SM, Waltham, MA. PEEK Biomaterials Handbook. 1st ed.: Elsevier Science; 2012; 1-7.

24. Najeeb S, Zafar MS, Khurshid Z, Siddiqui F. Applications of poly-etheretherketone (PEEK) in oral implantology and prosthodontics. J Prosthodont Res 2016;60:12-9.

25. Siewert B, Parra M, A new group of maretial in dentistry. PEEK as a framework material for 12-piece implant- supported bridges. Zahnarztl Implantol 2013;29:148-59.

26. 26. Tekin S, Değer Y, Demirci F . Evaluation of the Use of PEEK Material in Implant-Supported Fixed Restorations by Finite Element Analysis. Int. J. Clin Pract, 2019;22:9-15

27. AL-Rabab'ah M, Hamadneh W, Alsalem I, Khraisat A, Abu Karaky A. Use of high performance polymers as dental implant abutments and frameworks: A case series report. J Prosthodont 2017;28: 365-372

28. Patil R. Zirconia versus titanium dental implants: A systematic review. J Dent Implant 2015;5:39-42.

29. Linkevicius T, Vaitelis J. The effect of zirconia or titanium as abutment material on soft peri-implant tissues: A systematic review and meta-analysis. Clin Oral Implants Res 2015;26:139-47.

30. Bassi MA, Bedini R, Pecci R, Ioppolo P, Laritano D, Carinci F. Mechanical properties of abutments: Resin-bonded glass fiber-reinforced versus titanium. Int J Prosthodont 2016;29:77-9.

31. Stephan A, Steffen K, Frank K, Jörg L, Jörg N. A wealth of possible applications for high-performance polymers. 2013;39:2-10. 